\title{
A Study of Factors Influencing Students' Performances in Moroccan Open-Access Universities
}

\author{
Benaceur Outtaj
}

\begin{abstract}
In this study, we will try to show and explain a set of factors influencing the results of student registered in Moroccan open access faculties. We have chosen a sample of 1,500 students across different specialties in different university towns. Collected data will be analyzed using a data mining tool which is widely used in empirical studies especially in the social sciences field.
\end{abstract}

Index Terms-About student's performance factors, data mining, open-access universities.

\section{INTRODUCTION}

The role of higher education in creating responsible citizens and highly qualified staff is recognized both nationally and internationally. Indeed, a series of meetings, conferences and seminars are organized in several parts of the world to study the role of higher education in the development of society.

These activities witness the importance of the high-level education at the economic and social plan in every country. According to the UNESCO's recommendations, the higher education must [1]:

- $\quad$ Form highly qualified graduates.

- Educate responsible citizens by offering them appropriate qualifications.

- Promote a professional training that associates knowledge with high-level skills.

- Provide formations and programs which are permanently adapted to the present and future needs of society.

- $\quad$ Promote the knowledge through scientific research.

- $\quad$ Strengthen its services provided to society, mainly the activities intended to eradicate poverty, combat intolerance, violence and illiteracy.

- Further contribute to the development of the whole society.

- $\quad$ Contribute to development of the whole educational system, including the improvement of teacher training, curriculum development and educational research.

- And create a new society devoid of violence and exploitation, a society of highly-educated, motivated and integrated people.

In spite of the significant role of higher education, which is

Manuscript received April 25, 2013; revised August 1, 2013. This work was supported in part by E.R.A.D.I.A.S.S: « Equipe de Recherche en Analyse des Données et Informatique Appliquées aux Sciences Sociale »s is a research team affiliated to Faculté des Sciences Juridiques, Economiques et Sociales Souissi.

Benaceur Outtaj is with the Université Mohammed V Souissi, Rabat, Morroco (e-mail: b.outtaj@um5s.net.ma). manifested in the efforts deployed in the advances noticed in many domains as it referred to in the report established by M.E.S.R.S.F.C ${ }^{1}$ in 2012 , and which recommended the adequacy of the formations to sectorial development needs, the improvement of the internal and external performances, our higher education remains confronted with challenges and considerable difficulties regarding the formation of the highly qualified staff, the improvement of the quality of education and the relevance and efficiency of the programs. Other worrying problems come to amplify these difficulties: the perseverance, the wastage, the decrease, and the academic failure to relinquish. All this necessitates that our higher education has to find solutions to wastage before making other decisions [2].

\section{PRoblem And ObJectives of The STUdy}

The number of students in our higher education increases from one year to another, clogging all sectors, especially the universities of open access (313 220 students in 2009/2010, 373772 students in 2010/2011) [2].

Despite the establishment of new universities, the extension and rehabilitation of educational research institutions as well as the enhancement of the competencies of the professors and the administrative and technical staff, the challenge is even greater. Indeed, it is still difficult to provide an effective education and skills training that would account for a large number of students. Adding to this challenge, the organizational problem of registration often generates wrong orientations and decisions [2].

Due to the lack of space, students are forced to register in the first year of university at an open-access option although they want to join a safer regulated-access option. As a result, the least advantaged students usually fail in studies for which they are not prepared. These students do not all have the same abilities (same programs, same intellectual assets) to adapt to unintended learning situations. Consequently, they will not accomplish their studies. In other words, it will be harder for them to study and succeed in their first year of university and accordingly, they will have to quit university [3].

In this context, it would be relevant to question the factors which influence students' performances and the reasons behind their quitting university studies.

Some persistence and success factors have been highlighted by some researchers [3]-[4]. Indeed, studies in this area have categorized some factors of wastage and perseverance and determined number of elements in each category leading to abandonment or favoring perseverance

\footnotetext{
${ }^{1}$ M.E.S.R.S.F.C is the French abbreviation of Ministry of Higher Education, Scientific Research and management training.
} 
[5]. These factors include, among others, personal factors, learning factors, interpersonal factors, familial factors, institutional factors and environmental factors.

Further studies on the abandonment and perseverance have been carried out in recent years to better understand the phenomenon and explain the main factors [4]-[7].

Despite the multiple researches on the subject, mainly on educational wastage, very few statistical studies or surveys are carried out on the real factors that influence students' performances. Also, very little research has focused on the understanding of the difficulties that students encounter in accomplishing their studies.

For some researchers, the problem of the educational wastage is due to the lack of responsibility of some students and to their reluctance of being involved in the learning process. They assume that students who engage fully in their studies succeed and achieve their goals by obtaining their diplomas. In contrast, those who have no interest in their formation and training projects usually fail and quit or lag behind their degree course [8].

However, it should be noted that a number of factors that could profoundly explain the persistence and abandonment are not accounted for in these studies. Among them is the financial situation of the students, the motivation to pursue studies, the accuracy of the choice of the program, the pursuit or termination of studies and the decision to move away from the home town or to stay in.

This brief overview of these studies in the field indicates that they have all focused either on the identification of problems related to the academic progress of students or on identifying factors simply by explaining the rate of failure and wastage among them. To our knowledge, no previous published research has examined the key factors that influence students' performances and their impact on the persistence and success. For the afore-mentioned reasons, our research is particularly interested in determining the real factors that have a positive or negative effect on students' performances.

This empirical study or survey was conducted between 2011 and 2012. It therefore aims at providing some answers to questions related to this issue and raises many pertinent questions, such as:

- What are the most influential factors on student performances and what are the interactions between these factors?

- What are the real causes of educational wastage in open-access universities?

- What are the consequences?

- And how this can be remedied?

The determination of these factors is only possible if we first have sufficient data on the behavior of students towards their studies. Hence, for these data collection, it was necessary to conduct a statistical survey on students. This survey involved two key features: a relatively large sample, on the other hand, and a relatively detailed questionnaire that would take into consideration all the factors which might affect the student's success or failure, which is considered as one of the major axes of our ERADIASS research team.

In fact, this survey was conducted as part of a project funded by our university. It is designated to ensure a thorough and objective description of the lives of students by identifying the factors that influence their performance. It collected more than 1500 answers among which 901 subjects responded to a usable questionnaire of 80 questions related to several factors (age, gender, family structure, parents' level of education, living conditions, transportation, time management, lifestyle, behavior in the classroom, and more).

In the subsequent part, we present the methodology used in the research. This methodology provides an insight into the mode of administration of the questionnaire, its impact on the respondents to the questionnaire and on the analysts. It also describes the process used to collect and analyze data, including the problems encountered at all levels and the adjustments made. We deal with all kinds of results from the questionnaire. A detailed discussion of these results is also presented. Finally, we make some recommendations and conclusions to all actors concerned with the training/learning process (University, professors, government and others).

The interest of the project resides in:

- Its contribution to improve the success rate, also called "graduation rate" of students in open-access universities.

- Its contribution to improve the content of the proposed learning contents by analyzing some dependency relationships between the influencing factors.

- Its attempt to explain and justify the influence of certain factors or parameters, intrinsic or extrinsic (depending on the student's responsibility) on the students' results and on the quality of intermediate or final results.

The choice of the theme of our study is certainly determined by:

- The sample of the study population, which is in this case, a sample of students from open-access universities.

- The limitation of the survey in both space and time for the study is not limited to the city of our faculty but is extended to other university towns as well.

- The diversity of profiles of different members of our research team that includes various specialties: economists, econometricians, statisticians, computer specialists and specialists in the humanities and social sciences.

\section{Choice of FACtors AfFecting the Students' PERFORMANCE}

As is the case in any survey or statistical study, creating a questionnaire is needed as a first step before starting the other two steps, "data collection" and "analysis".

Based on the definition of a questionnaire as a "structured set of questions," the design and creating process of the questionnaire involves defining the basic or elementary questions and parties integrating these questions. All the art and know-how here consists of dividing the general problem "factors that influence students' performances in open-access universities", into sub-problems in the first phase and transform these sub-problems to elementary questions that the respondent will respond to. Furthermore, we assume that the underlying purpose of each question must reveal:

- A hypothesis that it is desired to be checked. 
- An indicator that is meant to be measured.

- Or a possibility of an existing relationship dependency between two or more factors.

For this, we held several meetings and discussions within our research team in order to define these questions and to decide on categorizing them first according to whether they are intrinsic or extrinsic (or endogenous or exogenous to the student): for which means, that factors where the student is responsible are considered as endogenous. These include the students' results and distinctions, and factors which are beyond his/her responsibility are treated as exogenous and these involve the financial situation, the educational level of parents and others. Note also that the main reason to introduce a factor in this list is probably its ability to affect the performances or the results of the students. Hypotheses remain to be verified by statistical methods and data mining after data collection throughout the survey. Finally, the choice is made on the definition of several groups of factors or issues that are the result of partitioning these groups of factors into9 categories or parties. The questionnaire is written in two languages: French and Arabic as they are the two main languages of communication used in these universities.

\section{A. Personal Information}

This group of questions informs us about age, sex, marital status, health status and readiness to study. The terms associated with these variables are detailed in the questionnaire.

\section{B. Previous Studies}

The type of baccalaureate, its sector (public, private, foreign mission), its distinction, and whether the student is repeater or not, can also influence the students' performance.

\section{Educational Qualifications}

University studies are entailed in this set of questions and include: the type of institution, the section or branch and the reasons for choosing it.

\section{Semesters Results}

The results of each semester reveal the validation or the failure in the semester; students are given the average grade of the semester in the case of validation of the semester or the list of non-validated modules in the opposite case.

\section{E. Conditions of Studies}

This set of questions tries to gather all the external (exogenous) factors that may influence the results of the students. It involves among other things, the pattern of absence if there is any, means of transportation used to reach the faculty, the logistics of studies, the rate of supervision and the conditions under which lessons are given, the conditions of preparing for exams and barriers against understanding the course, and even the students views on the coherence of the course or the coherence of the formation in general.

\section{F. Teaching Tools}

The availability of pedagogic tools can be used to understand and assimilate the teaching and subsequently ensure better student achievement. Some tools are linked to the students' social conditions such the owning of a computer and an internet connection. Other tools depend on providing the students with new educational resources such as online courses, the possibility of internet discussions to better understand courses.

\section{G. Social Status}

Social conditions in their economic and cultural sense are used in this group of factors to predict their influence on the results. Among these, we can cite family stability and parents level of education.

\section{H. Secondary Activities}

The goal here is to find out whether this type of activity would render the students more open-minded and improve their performances or not. We sub-emend here extra-academic activities such as cultural, community or political activities.

\section{Perspectives}

The student's motivation and his/her concerns about the near future may ultimately be a significant factor in determining the student performance.

Finally, note that this list of factors being developed does not pretend to be comprehensive nor exhaustive. It is the fruit of discussions of members based on their experiences and researches in the field of higher education as professors in open-access universities.

\section{The SAMPle Selection}

The quota method [9], [10] is the most common form (empirical or non-probabilistic method) adapted. It is used especially in the opinion polls and marketing research. So, our sample must be:

- A sample similar as much as possible to the university population in terms of structure. The investigator selects students to be interviewed according to a reasoned choice (but with some subjectivity and a relative freedom).

- A sample in which all the main variables explaining the characteristic of interest have to be included in the selection with the aim of limiting the selection bias.

\section{Description of Sample}

The study of the factors influencing the performance of students focused on a population belonging to different faculties in several university towns. The sample size was extended to 1500 individuals distributed among the faculties of Rabat, Salé, Kénitra, Casablanca, Agadir and Oujda with 150 students per institution. Apart from those of Oujda and Rabat where samples were also grouped along with the faculties of letters and sciences, all the other targeted institutions are faculties of law and economic sciences.

After the error-correction operation and adjustment (which is, sometimes, due to missing or incomplete data and to the absence of results related to main answers to the questions), we collected a database of 900 individuals whose age distribution indicates a concentration of age of 20 to 22, a fact which makes this group, by itself, represent almost $65 \%$ of students surveyed (Fig. 1).

As for gender, it shows that a large majority are females (over $58 \%$ of the respondents). From the overall study sample, 
only $4 \%$ are married. The overwhelming majority of the surveyed students come from public institutions (83\%), and most of them (over $86 \%$ ) belong to Scientific sections or literary ones ( $43 \%$ and $42.6 \%$ respectively).

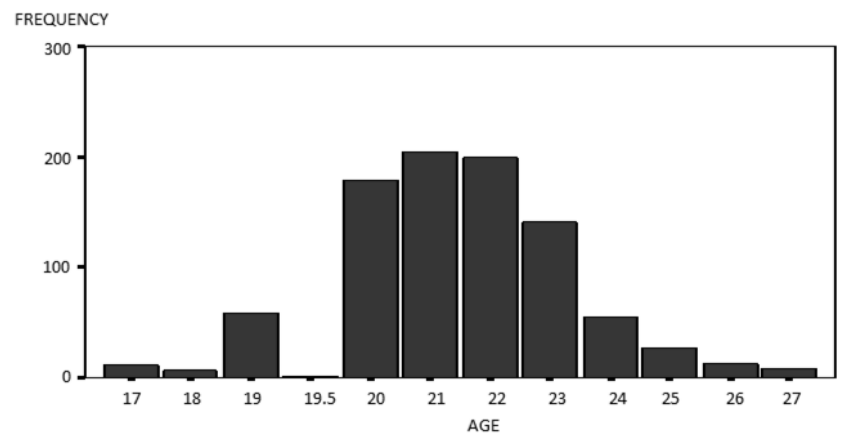

Fig. 1. Distribution by age.

\section{DESCRIPTIVE ANALYSIS OF SOME FACTORS}

We will make a representing frequency table a few factors that we consider interesting. An exhaustive analysis of the various factors may be included in a full report.

\section{A. Difficulties in Understanding the Courses}

Note that $70.48 \%$ of our sample have difficulties with their studies: $31.33 \%$ have problems with language especially when the courses are given in the French language, which is, apparently, a barrier for these students of whom $34.67 \%$ are likely to have a bad orientation, and $8.7 \%$ among whom encounter other types of problems such as: problems related to professors, classrooms/amphitheaters or overcrowded lecture halls and noisy students.

\section{B. What are the Causes that Disrupt Learning?}

Among the main causes that disrupt the learning process in classrooms, we can cite the entrance and/or exit of students during the course; $42 \%$ of the students selected this mode, while $31.67 \%$ complained about noise caused by students during course sessions, and $20.17 \%$ said that the noise of students outside the classroom disrupts the normal learning session; $12.67 \%$ are affected by the use of Cell-Phone during the courses.

\section{Reasons for Absence}

When analyzing the reasons for absence, we noted that there are three main reasons: $43.59 \%$ of the students are absent due to lack of transportation, $37.37 \%$ do not attend the course for health reasons, while $19.93 \%$ are absent because of the lack motivation, and $12.83 \%$ are absent because they do not understand the course.

\section{What Difficulties Do You Face in the Classroom?}

For the difficulties that students encounter in the classroom, $44.99 \%$ of them claimed that they face space problems (very limited area capacity), while $42.73 \%$ of them have difficulties related to the locals' organization and $40.18 \%$ of them answered that they suffer from the lack of equipment.

\section{E. How Do You Rate Your Relationship with the Professors?}

According to the data collected, the relationship between students and professors is not good at $100 \%, 18.89 \%$ of them have poor relationships with their professors; this, of course, affects the performance during their university degree course. The remaining $81.11 \%$ have normal relations.

\section{F. Do You Have a Computer?}

$86.10 \%$ of our interviewed students have computers at home, while $13.56 \%$ do not. This enlightens us already on the standard of living of our students. $86.10 \%$ of our samples are likely to have a standard of living beyond the average.

\section{G. What Are the Pedagogic Tools Do You Use?}

The majority of students use handouts in the first place to prepare their lessons with a percentage of $63.01 \%$. In the second place $36.2 \%$ use Internet. In third place $34.32 \%$ use books. The rest use encyclopedias and take notes in the classroom.

\section{H. Why Do You Not Understand Your Courses?}

$38.28 \%$ of students do not understand their courses because of the accumulation of these courses. $33.73 \%$ of the respondents say that the course does not contain enough examples, which makes it difficult to understand. $28.6 \%$ of the students do not follow the course quite well because of the speed of presentations of their professors. $28.45 \%$ believe that the presentation of the course is not quite clear, which is an obstacle to understanding. $20.4 \%$ fail to assimilate their courses due to the lack of time devoted to the review.

\section{Do You Have an Internet Connection at Home?}

The percentage of students having an internet connection at home is $83.33 \%$. This percentage is very significant and shows that the standard of life of our population is greater than or equal to the average living standard in general. (Hence, it can be concluded that the majority of students reaching the Moroccan universities are of average living standard)

\section{J. How Many Hours a Week Do You Spend Online?}

The majority of students $(75.3 \%)$ spend more than 4 hours per week on the internet, and $21 \%$ of them spend less than 4 hours per week. Meanwhile, the students use the Internet to chat $(60.67 \%)$ or resort to discussion forums $(27.68 \%)$, whereas a minority of them uses it for studies (only $0.23 \%$ ). This attraction to the "chat" may have a negative influence on the students' performances.

\section{K. Do You Have a Transportation Problem?}

Transportation has always been a problem for students. $70 \%$ of them find it difficult to join their faculties. $54.17 \%$ use the bus for transportation, $18.54 \%$ walk. Others use either the taxi or the train. Based on this, we can conclude that the bus is the number one means of transportation for most students, but it is a real headache, since there is a great disproportion between the number of students and that of buses (the number of buses has decreased compared to the number of students), which obviously leads to delays, absence and more.

\section{What are Your Plans after the Bachelor University Degree?}

Prospects for students after their Bachelor degree: $64.37 \%$ would like to continue their studies, that is to say, enroll in doctorate or specialized masters degrees, while the rest $(34.95 \%)$ would hope to be integrated in the labor market. 


\section{Do You Have Concerns to Find a Job After Graduation?}

The majority $(77.47 \%)$ of our students has the same concerns and fears of not finding work after graduation, $43.55 \%$ of them are concerned about the mismatch between training and the demands of the labor market. $34.19 \%$ are afraid of discrimination in access to employment, while $22.25 \%$ of them have wage concerns.

These concerns will undoubtedly influence their studies. $61.01 \%$ selected the answer "Yes" to the question whether these concerns would affect their studies.

\section{ANALYSIS OF VARIANCE (ANOVA)}

The approach adapted is to perform a bivariate analysis using a statistical comparison of means. This bivariate analysis reveals the set of explanatory variables that are statistically significant and which have direct impact on the dependent variable. To consolidate our results, analysis of variance (ANOVA) is used as a test.

The analysis of variance is a family of methods used to express and interpret the average differences observed between groups for the same variable. This kind of analysis is enabled within the general framework of the linear model, where a quantitative variable is explained by a qualitative variable.

ANOVA is used to check if there are differences in means between sub-groups by studying their variance. The null hypothesis is tested by the F-test in SPSS tool [11]. The significance level used was $5 \%$. We test the hypothesis of the absence of a relationship between two variables by examining the p-value corresponding to F-calculated. If the p-value is less than 0.05 , then we reject the null hypothesis.

The homogeneity of the variance group and normality of the data are checked successively using the Levene test (null hypothesis that the variances are equal in groups) and Kolmogorov-Smirnov test (null hypothesis: the normal distribution).

Tests and analyses are performed by groups of variables in accordance with their order and code given in the questionnaire. To perform this analysis, we have chosen the average score of the student as a dependent variable to represent the student result or the student's performance. The bivariate analysis is to change the explanatory variable studying the influence regularly. Below are some examples of bivariate analysis:

\section{Influence of Personal Information on the Results}

In this block of variables where there are age, sex, marital status, and availability to conduct the studies. Only the variable how to conduct studies is statistically significant: home institution and the sector of students belong to may explain the difference in means. The full-time course students do better than others. This is particularly true for the first year and for the last year of the course.

Against all expectations, the type of baccalaureate has no effect on the average student. The students seem to adapt to the requirements of the university studies and previous studies have no more effect on their performance.

1) Being a repeater or a new student to the baccalaureate affects the performance of the student. The test shows that this variable is significant and explains the change in average. Regarding their marks, Non-repeaters do relatively better than repeaters. The loss of confidence and lack of motivation may be the reason behind the poor performance of these students. In contrast, the test on the average score of S1 (First semester at the university) does not provide any significant results.

2) The baccalaureate with distinction directly affects students' performance. It is statistically significant and helps to explain the overall average or score. Students with high grades in the Baccalaureate get better results than others.

3) The overall average or score is not affected by the high school of origin of the student. A slight difference in means is marked between the private and the public sectors. Students with a foreign baccalaureate (like students from other African countries) come in the third place. Over all, the test is not significant and therefore, we cannot presume that the school of origin explains or influences the student's performance.

4) The result of the test of the variable regarding the type of barriers against understanding shows that students who have language problems have lower scores than others. This result reinforces the test for the understanding of the course. It means that if a student has problems with language, he/she will have difficulty understanding the course.

5) In parallel, the test indicates that the timetable has no impact on student's performance.

6) The test also shows that to prepare for the exam in groups does not affect the result. The way of preparing for exams is not statistically significant.

7) There is a real difference on the scores frequency of the rate of the students' attendance at the courses. Regular attendance of the courses significantly improves the students' score or performance. The variable of attendance clearly explains the performance of students. This is clearly confirmed by the statistical test.

8) This study focuses on the influence of the classroom size or area. The way the student views classrooms; loaded or normal. The analysis shows that $56 \%$ of them think that the groups are large sizes, while the $44 \%$ of them find it normal. The statistical study shows that this variable has no effect on students' performance.

9) The study focuses also on classroom participation. The statistical study shows that students who participate in the classroom succeed and obtain good results. This is confirmed by the study of the ANOVA, since the test of significance is $0.1 \%$.

Accordingly, this variable better explains the performance of the student.

\section{Multiple CoRRESPONDENCE ANALYSIS MCA}

After the consolidation of the database and the review of various methods of implementation of a Multiple Correspondence Factorial analysis [12], we present the main results obtained with the SPSS statistical tool [11].

Rule: When a specific eigenvalue is above the average of all the eigenvalues then it is remarkably significant and the factorial axis is eligible. 


\section{Discrimination Measures}

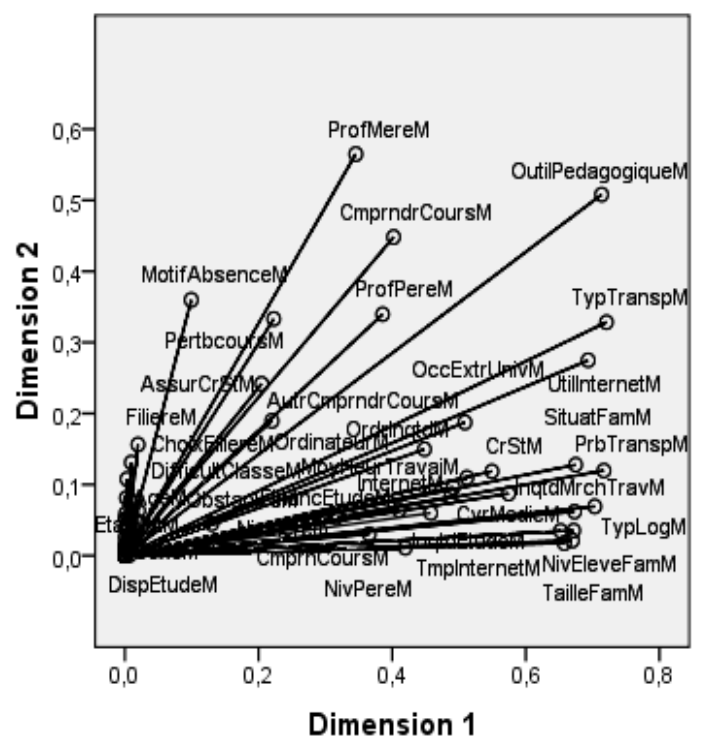

Variable Principal Normalization.

Fig. 2. Discrimination analysis generated by SPSS tool.

Roughly the students' performance depends primarily on the first factorial axis which reflects the mentality of the student. As shown in Fig. 2, this mentality consists of thirteen variables, nine of which are strongly related to performance. These are: Means of transport; pedagogic Tools; the way of using of the Internet; unity of the family; cost of studies; Prospects after graduation; Concern about the labor market; Average working time; and tutoring.

These variables inform us about the beliefs and values that the student has received from his/her family (family unity, the use of the Internet, the higher level of family education, perspectives after graduation and ability to overcome obstacles (Mode of Transport, Average work, educational tools, extra-courses or tutoring). Moreover, the second factorial axis composed of the mother's occupation also contributes to the explanation of student's performance. Finally, we retain a total of ten variables.

Note that the mentality of the student depends mainly on his/her personality and mood. It may be subject to changes at any moment; perception, attitude and actions can then change. These factors as mentioned earlier are intrinsic to the student or endogenous to the student. In contrast to this, the mother's profession or other exogenous factors falls his/her "destiny". They are beyond the student's control as cannot change these factors. The good news is that the MCA shows that the influence of mentality weigh much more on the student's performance than do the exogenous factors like the mother's profession.

Finally, the MCA shows that student success in the first semester is an indicator of his/her overall performance at the end of their studies. The question, however, is whether there are other performance indicators to be adapted for our sample.

\section{CONCLUSION}

The present is research an attempt to investigate some factors influencing the performance of students in open-access universities. It is based on a survey conducted in spring 2012 on a sample of 1,500 students across several Moroccan universities. Using a questionnaire with 80 questions and 901 usable responses on SPSS, we tried to identify, as far as possible, all the factors that may positively or negatively influence the performance of the student.

The questions, which form the study variables, are classified into 9 groups: personal information, previous studies, university studies, semester results, pedagogic Tools, Social Status, Prospects and secondary activities. The values of the endogenous variable, which represents the performance of students, are determined by calculating the average score for different semesters.

To answer this problem and to determine ipso facto the most significant variables, we used a statistical approach based on bivariate analysis completed by MCA.

The results of our analysis show that among the set of variables taken into account, almost $50 \%$ have no significant influence on the students' performances. In addition, some results are cons-intuitive as is the case of the variable "type of baccalaureate" that has no effect on the overall score. This can be applied to the factor of tutoring and to the educational level of parents. In this sense, we remained vigilant about the interpretation of results without explaining their reasons. The problems of accuracy of the data and the conditions of their collection may be responsible for such contingencies. It should be noted that these variables, when treated separately, are not significant but may be in interaction with other variables.

However, the factors that explain the overall score, such as the availability to study, attendance of seminars or practical works, the distinction of the Baccalaureate diploma, the understanding of the courses, the problem of language, the computer ownership, the relationships between students and professors, on the one hand and between students and the administration, on the other hand, and many other variables, which generally prescribe the teaching staff attitudes in these universities.

The bivariate statistical analysis is not without limitations, and to support our approach we used MCA to extract the most relevant set of variables and explain them to better understand student performance. The results of this analysis indicate that, in general, the performance of the student depends primarily on the first factorial axis which we called the mentality of the student. It consists of thirteen variables where only nine of which are strongly related to performance. These are:

1) Means of transport;

2) Teaching Tools;

3) Use the student is doing the Internet;

4) Unity of the family;

5) High-education level of family members;

6) Prospects after graduation;

7) Concerns about the labor market;

8) Average working time;

9) Extra-courses or tutoring.

Furthermore, the MCA shows that the students' success in the first semester is an indicator of his/her overall performance at the end of his/her study. The results of the MCA do, to a certain degree, strengthen the findings of the 
bivariate analysis. Educational tools, attendance of directed works courses, level of education of parents, time spent at work and issues related to the understanding of the course are the factors that best explain the performance of students.

\section{ACKNOWLEDGMENT}

I would like to thank all members of the ERADIASS team (A. Boussari, A. Chaoui, A. Danine, M. Dinia, A. Elghini, S.Elouardirhi, F. Meslouhi, R. Raouf, S. Toufik, and A. Yousfi) for the tremendous work they have done to complete this study.

\section{REFERENCES}

[1] UNESCO Document. (October 1998). World Declaration on Higher Education for the Twenty-first Century: Vision and Action and Framework for Priority Action for Change and Development in Higher Education. [Online]. Available: http://www.unesco.org/education/educprog/wche/declaration_eng.htm

[2] M. E. S. R. S. F. C. The contract development of the university. 2009-2012.Progress Report 2011. [Online]. Available: http://www.enssup.gov.ma

[3] L. Sauvé et al. (June 2007). The abandonment and persistence in postsecondary education. SAMI-Persévérance, Final report. [Online]. Available:

http://www.frqsc.gouv.qc.ca/upload/editeur/actionConcerte/RF-LSau ve.pdf

[4] L. Tremblay, The issue of success in higher education, P. Chenard and P. Doray Eds. Presses de 1'Université du Québec, 2005, ch. 5, pp. 84-108.

[5] M. Loiselle et al., An analysis of the determinants of perseverance and success of Aboriginal students at the University of Quebec in Abitibi-Témiscamingue. Researsh report, Université du Québec en Abitibi-Témiscamingue, Canada, February 2010.

[6] D. Barbeau, Educational Interventions and Success in College: A Meta-Analysis, Presses de l'Université Laval, 2007, ch. 4-5, pp. 63-103.
[7] M. Romainville, L'échec dans l'université de masse, Paris, l'Harmattan, 2000.

[8] Conseil Supérieur de l'Education C. S. E, At the college, the student engagement in their learning plan, Bibliothèque et Archives Nationales du Québec, Canada, March 2008.

[9] J. Y. Baudot. The survey purposive. [Online]. Available: http://www.jybaudot.fr/Sondages/quotas.html

[10] TNS ILRES. The quota method. [Online]. Available: http://www.tns-ilres.com/cms/Home/WikiStat/La-methode-des-quotas

[11] IBM Software. The SPSS Software. [Online]. Available: http://www-01.ibm.com/software/analytics/spss/

[12] D. Desbois, "Multiple Correspondences Analysis in a Netherlands way: Introduction to the analysis of homogeneity," Revue MODULAD, no. 38 , pp. 194-244, 2008.

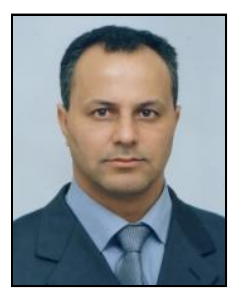

Benaceur Outtaj was born in 1967 in Khemisset (Morocco). He holds a degree in applied mathematics and a specialty degree graduate in Computer Science. For this purpose he prepared a thesis on formal description techniques and their applications to formalize and compare multimedia protocols. This work has been a joint publication in the international journal "Computer Communications" in 2000 and several papers in national conferences. In 2011, he obtained the degree of "Habilitation Universitaire" which enables him the supervision of PhD students. From 1994 to 2000, he worked as a professor assistant at the Faculty of Science and Technology of Beni-Mellal (Morocco) and since 2000.

$\mathrm{He}$ is a Professor Researcher of computing sciences and applied mathematics at the Faculty of juridical, economical and social sciences affiliate to Mohammed V Souissi University in Rabat (Morocco). He is co-founder of the research team ERADIASS which currently works on data mining and computing science applied to social sciences. He is also interested in the integration of new technologies and particularly computing and e-services in live. He is the author of many papers and has participated in several scientific events in Morocco and abroad on topics related to e-learning, e-trading, e-voting and e-commerce in order to ameliorate electronic governance in Morocco. 